\title{
The Flow Properties of an Extracellular Mucopolysaccharide Produced by a Marine Strain of Pseudomonas
}

\author{
Suda Tandavanitj, ${ }^{*}$ Eizo Miki, ${ }^{*}$ and Koichi Okutani* \\ (Received May, 1, 1990)
}

\begin{abstract}
The flow properties of the highly viscous mucopolysaccharide produced by a marine strain of Pseudomonas (No. 9-12) were investigated. The aqueous solutions of both the native and depyruvated forms of this mucopolysaccharide had yield values even at low concentrations. Flow indices for the native form increased with increasing concentrations, but remained constant for the depyruvated form at various concentrations. The structural viscosity of both the native and depyruvated forms increased with increasing concentration. The spinnability of the native form was determined to be much greater than that hyaluronic acid and potato starch. Electron micrographs of the gel of the native form showed microfibrils with network structures.
\end{abstract}

We previously isolated a strain of mucopolysaccharide-producing bacteria from seawater. A characteristic feature of this bacterium (strain No. 9-12 ) is the production of a highly viscous extracellular mucopolysaccharide. ${ }^{17}$

The purified polysaccharide is composed of galacturonic acid, galactose, glucosamine, galactosamine, alanine, and pyruvic acid in the relative molar proportions $1.7: 1.0: 1.1: 2.5: 1.2: 1.3$, together with acetyl groups.

In the present investigation, we have studied the flow properties, non-Newtonian behavior and spinnability of aqueous solutions of this mucopolysaccharide. We also report the results of studies $\mathrm{c} n$ the microstructure of the polysaccharide gel.

\section{Materials and Methods}

\section{General Methods}

The general methods and procedures of isolation and purification of extracellular mucopolysaccharide from marine strain (No. 9-12) of

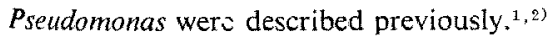

\section{Depyruvated Polysaccharide}

The polysaccharide $(40 \mathrm{mg})$ was heated with $1 \mathrm{~mm}$ oxalic acid in $0.1 \mathrm{M} \mathrm{NaCl}(20 \mathrm{~m} /)$ for $2 \mathrm{~h}$ at $100^{\circ} \mathrm{C}$. The hydrolyzate was dialyzed against deionized water, and then freeze-dried.

The product was checked for purity by sedimentation and electrophoretic analyses, as previously described. ${ }^{2}$ )

\section{Sugar Analysis}

Hydrolysis of the polysaccharide and sugar analysis were conducted as described previously. ${ }^{1)}$

For determination of the average molecular weight by gel-filtration analysis, an Asahipak GFA $7 \mathrm{M}$ column (Asahi Chemicals, $7.6 \times 500 \mathrm{~mm}$ ) was used. For minimizing the association effect of the polysaccharide solution, an aqueous $0.1 \mathrm{M}$ $\mathrm{NaCl}$ was used as a mobile phase at $30^{\circ} \mathrm{C}$ and a flow rate of $0.4 \mathrm{ml} / \mathrm{min}$. A Shodex Standard Kit P-82 (Showa Denko, M.W. $=0.58 \times 10^{4}-85 \times 10^{4}$ ) was used for calibration of molecular size.

\section{Measurements of Viscosity and Spinnability}

Measurements of viscosity were performed at $25^{\circ} \mathrm{C}$ with a cone and plate viscometer ${ }^{33}$ (Model E, Tokyo Keiki Co.), having a cone angle of $1^{\circ} 34^{\prime}$, a cone radius of $4.8 \mathrm{~cm}$, and a sample volume of $1.0 \mathrm{~m} /$.

Measurements of spinnability were performed at $20^{\circ} \mathrm{C}$ using a Yamaden rheometer RE 3305 with a polyacetal cylinder as a plunger ( $3 \mathrm{~mm}$ diameter). After a plunger penetrated $1 \mathrm{~mm}$ below the surface of the sample fluid, the sample plate was driven downward by a motor at $1 \mathrm{~cm} / \mathrm{sec}$. The sample fluid made a strand from its surface to the plunger head. The point at which the strand broke was used as a measure of spinnability and expressed as the maximum length of the strand. Potato starch (Wako Pure Chemicals) and hyaluronic acid (Kyowa Hakko Kogyo) were used as the reference samples of spinnability.

Shear rate (D), shear stress $(\mathrm{S})$, and apparent

* Faculty of Agriculture, Kagawa University, Miki, Kita, Kagawa 761-07, Japan (S. Tandavanitj, 三林 英三，奥谷康一: 香川大学嚳学部). 


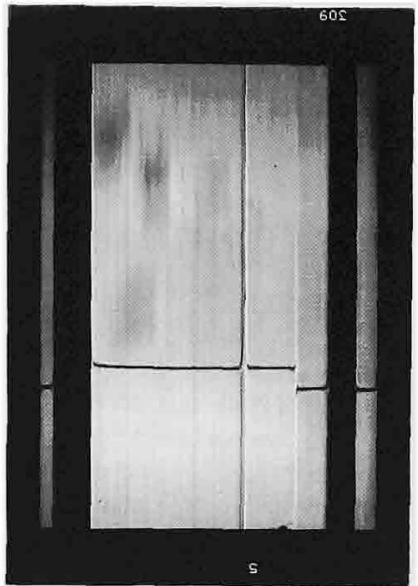

Fig. 1. The sedimentation pattern of the depyruvated polysaccharide. The measurement was made in $0.1 \mathrm{M} \mathrm{NaCl}(2.5 \mathrm{mg} / \mathrm{ml})$ at $25^{\circ} \mathrm{C}$. The photograph was taken $80 \mathrm{~min}$ after the maximum speed $(60,000 \mathrm{rpm})$ was obtained. The direction of sedimentation was from right to left.

viscosity were calculated from the equation of Margules. ${ }^{4)}$

\section{Scanning Electron Microscopy}

Hyaluronic acid was used as the reference sample of mucopolysaccharide. After fixing with $1 \%$ osmic acid for $1 \mathrm{~h}$, the polysaccharide gel $(1 \%$ aqueous solution) was dehydrated using a series of increasing concentrations of acetone in water, with the final dehydration step in absolute acetone. Samples were then dried in a critical point dryer (Hitachi HCP-1) using liquid carbon dioxide, and these samples were stuck to aluminum studs with bond. The samples were coated with platinum by vacuum evaporation and were examined with a Hitachi S-800 scanning electron microscope operating at an accelerating voltage of $20 \mathrm{kV}$.

\section{Results and Discussion}

\section{Depyruvated Polysaccharide}

The method used did not result in complete
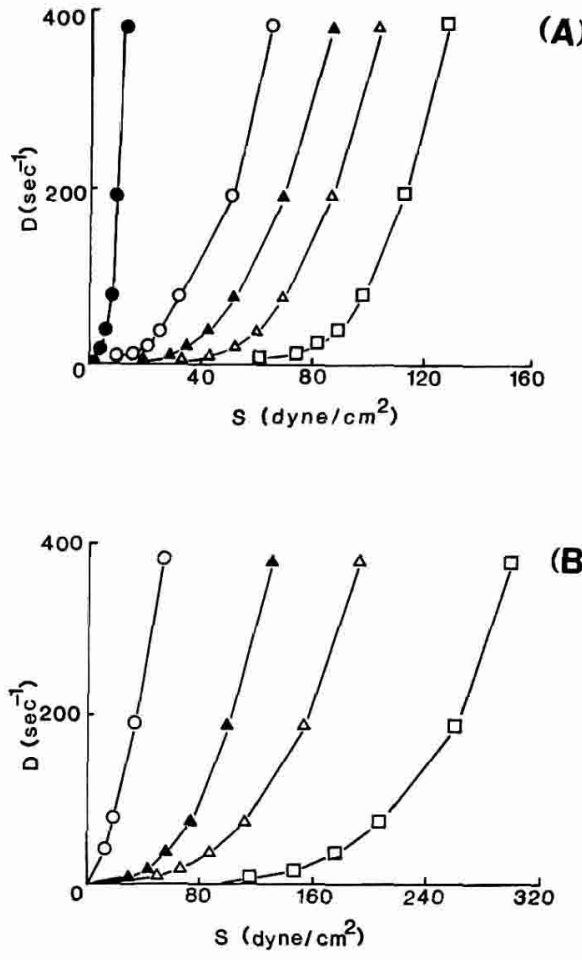

Fig. 2. Flow curves of the polysaccharide at various concentrations.

(A) Native form, (B) Depyruvated form. - $0.1 \%, \bigcirc 0.25 \%, \Delta 0.5 \%, \triangle 0.7 \%, \square 1.0 \%$.

depyruvation of the polysaccharide. However, complete depyruvation by a stronger hydrolysis caused partial depolymerization of the polysaccharide.

An aqueous solution of the depyruvated polysaccharide preparation produced by the method described showed a higher viscosity than the native polysaccharide. The depyruvated form was homogeneous according to both ultracentrifugal (Fig. 1) and electrophoretic analyses. The approximate sedimentation coefficient was calculated to be $2.1 \mathrm{~S}$, which is less than that of the native polysaccharide. ${ }^{1)}$ The molecular weight was estimated to be $1.9 \times 10^{6}$, whereas that of the native form

Table 1. Chemical composition of the depyruvated polysaccharide

\begin{tabular}{ccccccc}
\hline \hline \multirow{2}{*}{ Polysaccharide } & \multicolumn{7}{c}{ Molar ratios } \\
\cline { 2 - 7 } & GalUA & Gal & GlcN & GalN & Ala & Pyr \\
\hline Depyruvated & 1.7 & 1.0 & 1.0 & 2.5 & 1.0 & 0.4 \\
Native & 1.7 & 1.0 & 1.1 & 2.5 & 1.2 & 1.3 \\
\hline
\end{tabular}

Compositions are expressed as molar ratios relative to Gal (1.0). GalUA, galacturonic acid; Gal, galactose; GleN, glucosamine; GalN, galactosamine; Ala, alanine; Pyr, pyruvate. 

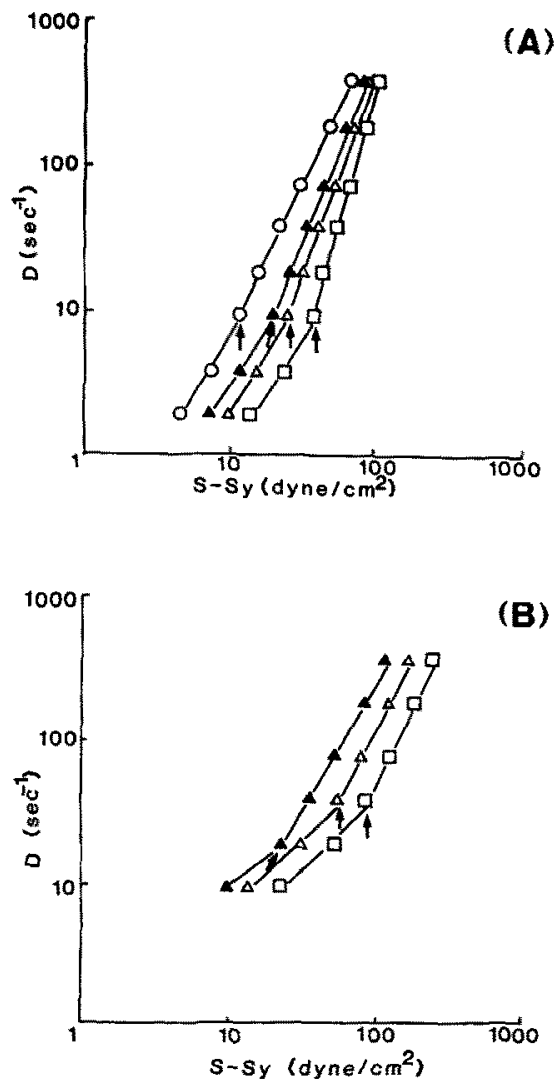

Fig. 3. Logarithmic plots of shear rate versus shear stress for the polysaccharide at various concentrations.

(A) Native form, (B) Depyruvated form. $0.25 \%, 0.5 \%, \Delta 0.7 \%, \square 1.0 \%$. Refraction point.

was estimated to be $3-4 \times 10^{6}$.

Component analysis showed that some of the pyruvic acid was lost from the native form (Table 1), but other components were not changed during the depyruvation procedures. This suggests that the depyruvation procedure (although a partial depyruvation) does not cause a modification of the polymeric structure of the native form.

\section{Viscosity}

Flow curves for various concentrations of the native and depyruvated polysaccharide are shown in Fig. 2. The yield value was not observed at the $0.1 \%$ solution of the native form, but the $0.25,0.5$, 0.7 , and $1.0 \%$ solutions had the yield values ${ }^{5,6)}$ (Fig. 2A) which were estimated to be 5.3, 10.2, 20.3 , and $38.4 \mathrm{dyn} / \mathrm{cm}^{2}$, respectively, suggesting
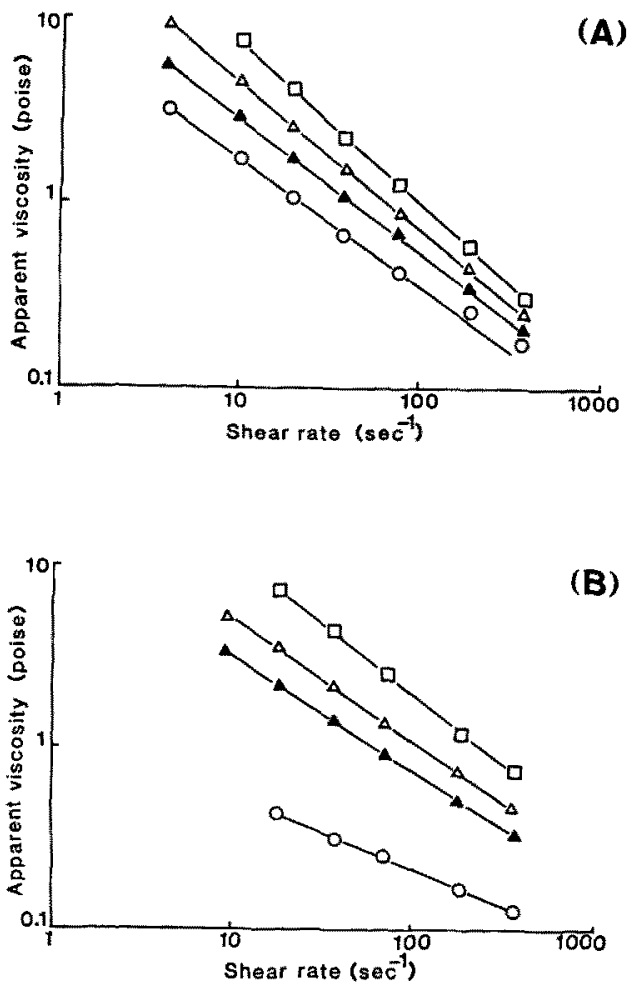

Fig. 4. Logarithmic plots of apparent viscosity versus shear rate for the polysaccharide at various concentrations.

(A) Native form, (B) Depyruvated form. $0.25 \%, \triangle 0.5 \%, \triangle 0.7 \%, \square 1.0 \%$.

Table 2. Spinnability of the polysaccharide

\begin{tabular}{cc}
\hline Polysaccharide & Spinnability $(\mathrm{cm})$ \\
\hline $1 \%$ Native form & 2.03 \\
$1 \%$ Hyaluronic acid & 0.52 \\
$2 \%$ Potato starch & 0.94 \\
$4 \%$ Potato starch & 1.28 \\
\hline
\end{tabular}

Potato starch was heated at $90^{\circ} \mathrm{C}$ for $10 \mathrm{~min}$.

that there are secondary associations between the polysaccharide chains. ${ }^{4,7,8}$ The behavior of nonNewtonian flow of this polysaccharide was similar to that of xanthan gum $^{\text {7) }}$ and the polysaccharide from Bacillus polymyxa, but differed from the polysaccharide from Coryneform bacteria ${ }^{10}$ which has no yield value at various concentrations.

The $0.25,0.5,0.7$, and $1.0 \%$ solutions of the depyruvated form had the yield values (Fig. 2B) which were estimated to be $3.2,23.0,38.4$, and $96.0 \mathrm{dyn} / \mathrm{cm}^{2}$, respectively. A more pronounced secondary association of the depyruvated form was observed than for the native form at the 
various concentrations, suggesting the association characteristics of this mucopolysaccharide were altered after depyruvation.

To estimate non-Newtonian behavior quantitatively, the above results were applied to the power law calculated from the equation of Herschel and Bulkley. ${ }^{11)}$ The flow curves were separated into two straight lines, and refraction points were determined for the various concentrations (Fig. 3A). Thus, the flow indices were nearly constant (1.9-2.2 dyn $/ \mathrm{cm}^{2}$ ) before the refraction point, but increased $\left(2.2-4.1 \mathrm{dyn} / \mathrm{cm}^{2}\right)$ with the increasing concentration after the refraction point. The flow behavior indices of this polysaccharide differed from those of xanthan gum $^{7)}$ and the polysaccharides from B. polymysxa $a^{9)}$ and Coryneform bacteria. ${ }^{10)}$

For the depyruvated form, the flow indices were nearly constant for the various concentrations both before (0.9-1.0 dyn $\left./ \mathrm{cm}^{2}\right)$ and after (2.1-2.4 dyn/ $\mathrm{cm}^{2}$ ) the refraction point (Fig. 3B).

The relationship between the $\log$ of apparent

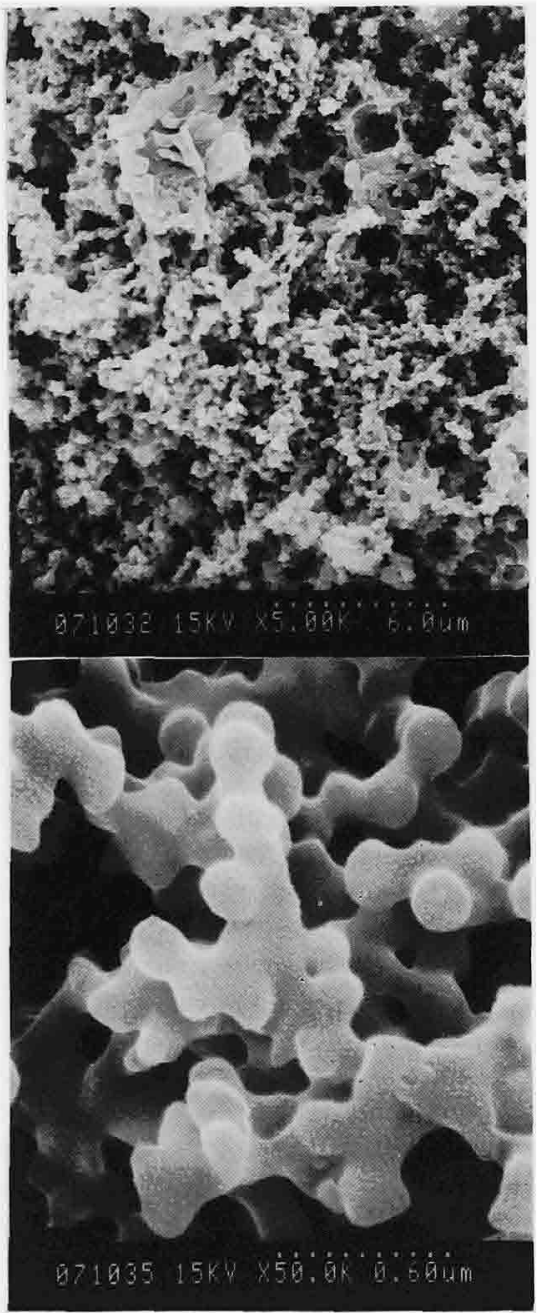

(A)

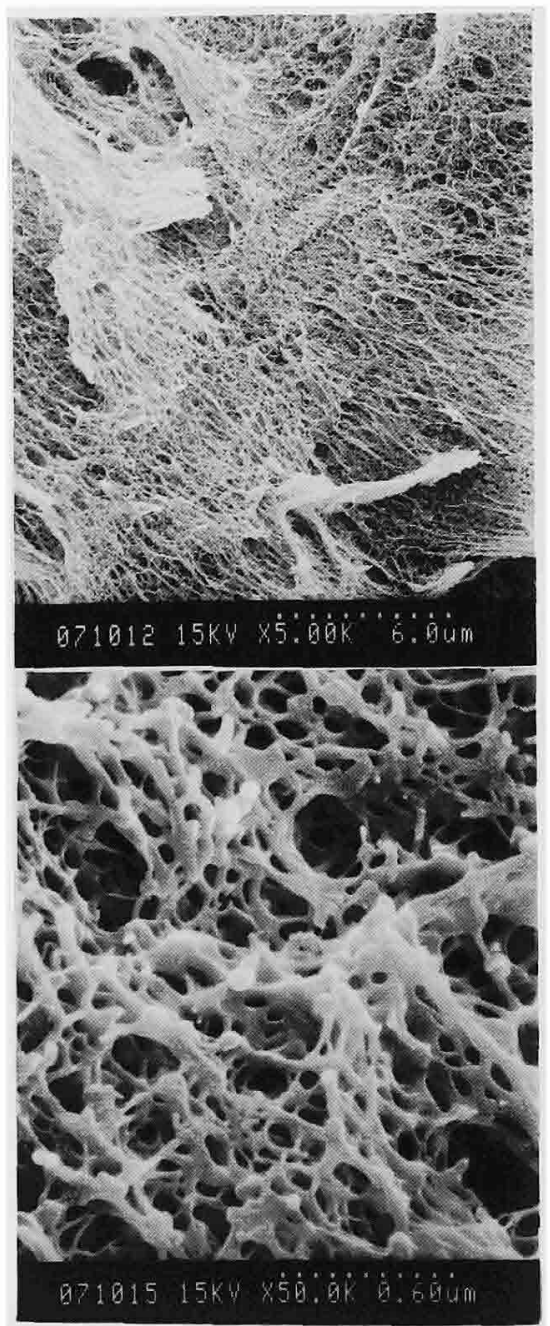

(B)

Fig. 5. Electron micrographs of polysaccharide gels.

(A) Hyaluronic acid.

(B) Native polysaccharide produced by marine Pseudomonas. 
viscosity and the log of shear rate was linear over a shear rate range from less than 10 to $384 \mathrm{sec}^{-1}$ (Fig. 4). The log of apparent viscosity of both the native and depyruvated forms decreased linearly with increasing the $\log$ of shear rate, and the slope changed with concentration. The sopes for the $0.25,0.5,0.7$, and $1.0 \%$ solutions of the native form were estimated to be $-0.52,-0.69,-0.72$, -0.74 , and -0.87 , respectively (Fig. 4A). These values seemed to be similar to those of xanthan gum $^{7)}$ and the polysaccharide from $B$. polymyxa. ${ }^{2)}$ Those for the $0.25,0.5,0.7$, and $1.0 \%$ solutions of the depyruvated form were estimated to be -0.38 , $-0.65,-0.67$, and -0.72 , respectively. The results indicate the structural viscosity of both forms increases with increasing concentration, while the native form has a greater slope than the depyruvated form at the same concentration.

It is known that pyruvate residues of polysaccharides contribute to their intramolecular association. ${ }^{12)}$ The present results indeed suggest that the pyruvic acid associated with this polysaccharide contributes to interactions among the polysacchride chains.

\section{Spinnability}

The spinnability of the polysaccharide preparation was estimated by comparison with potato starch and hyaluronic acid. Potato $\operatorname{starch}^{13)}$ and hyaluronic acid"4) are known to show high viscosities and strong spinnabilities. Especially, among polysaccharides, potato starch has been studied extensively for estimating the correlation between flow behavior and spinnability. Results indicate that the spinnability of the native form is greater than that of potato starch and hyaluronic acid (Table 2).

\section{Observations by Scanning Electron Micrography}

Electron micrographs of gels of the native polysaccharide and hyaluronic acid are shown in Fig. 5. Hyaluronic acid showed particulate structure at the lower magnification, but showed microfibrils of about $1,000 \AA$ width and with irregular swellings at the higher magification. The
Psendomonas polysaccharide showed microfibrils with network structures at both the lower and higher magifications. The width of the microfibrils was about $200-600 \AA$. Thus, the microfibrillar structure of this polysaccharide is similar to that of curdlan gels. ${ }^{15)}$

\section{Acknowledgments}

We are grateful to Dr. S. Tajima and Dr. K. Takegawa of Kagawa University for measurements of amino sugar and sedimentation analysis, respectively.

\section{References}

1) S. Tandavanitj, S. Ishida, and K. Okutani: Nippon Suisan Gakkaishi, 55, 2015-2019 (1989).

2) S. Tandavanitj and K. Okutani: Nippon Suisan Gakkaishi, 55, 1845-1849 (1989).

3) M. C. Bourne: "Food Texture and Viscosity", Academic Press, New York, 1982, pp. 236-237.

4) S. Kuroiwa and M. Nakamura: Kōgyo Kagaku Zasshi, 67, 1624-1629 (1964).

5) T. Nakagawa and H. Kanbe: "Rheology", Misuzu Shobo, Tokyo, 1964, pp. 269-270.

6) B. Tamamushi: in "Rheology Handbook" (ed. by Kobunshi Gakkai), Maruzen, Tokyo, 1965, p. 106.

7) M. Tako, T. Nagahama, and D. Nomura: Nippon Nōgeikagaku Kaishi, 51, 513-518 (1977).

8) S. Kuroiwa and M. Nakamura: Kögyo Kagaku Zasshi, 67, 1629-1634 (1964).

9) M. Tako: Nippon Nögeikagaku Kaishi, 51, 591$596(1977)$.

10) M. Tako, T. Nagahama, and D. Nomura: Nippon Nögeikagaku Kaishi, 51, $397-403$ (1977).

11) M. C. Bourne: "Food Texture and Viscosity", Academic Press, New Yorok, 1982, pp. 217-218.

12) M. Tako and S. Nakamura: Agric. Biol. Chem, 48, 2987-2993 (1984).

13) K. Hirao, Y. Murayama, H. Akabane, and N. Nakahama: Kaseigaku Zasshi, 36, 10-17 (1985).

14) G. J. Bonde, F. E. Carlsen, and C. E. Jensen: Acta Pharmacol. et Toxicol., 13, 205-212 (1957).

15) F. Takahashi and T. Harada: Kaseigaku Zasshi, 37, 251-256 (1986). 